\title{
COVID-19 Vaccine Acceptability Among Women Who are Pregnant or Planning for Pregnancy in Saudi Arabia: A Cross-Sectional Study
}

\author{
Mohammed Samannodi (D) \\ Department of Medicine, Umm AI Qura \\ University, Mecca, Saudi Arabia
}

\begin{abstract}
Purpose: Few studies in the literature deal with the acceptance of being vaccinated while pregnant. This study aimed to investigate the acceptance rate of the COVID-19 vaccine among pregnant women and those who are planning for pregnancy in Saudi Arabia.

Methods: This cross-sectional study used an online self-administered questionnaire in Saudi Arabia between 12 June and 1 August 2021. The first section described the demographic characteristics of the study participants (five items), participants' perceptions about COVID19 (three items), participants' hesitancy about receiving the COVID-19 vaccine (nine items), perceived benefits of receiving the COVID-19 vaccine (four items), and motivations and causes of action for receiving the COVID-19 vaccine (three items).

Results: A total of 431 women who met the inclusion criteria were involved in this study. The study participants showed moderate scores in terms of their COVID-19 vaccination perception, hesitancy, perceived benefits and causes of action that ranged between $53.3 \%$ and $65.0 \%$. The mean perception score for all participants was 8.0 (standard deviation (SD): 2.8 ) out of 15. The mean hesitancy score for was 27.6 (SD: 7.3) out of 45. The mean perceived benefits score was 13.0 (SD: 4.5) out of 20. The mean causes of action score was 9.0 (SD: 3.7) out of 15. Pregnant women or those who are planning to be pregnant are more hesitant to receive the COVID-19 vaccination $(\mathrm{p}=0.001)$. Those aged below 29 years who reported receiving the COVID-19 vaccine showed higher levels of perceived benefits $(p<0.05)$.

Conclusion: Pregnant women and those who are planning to be pregnant have a moderate score in terms of their COVID-19 vaccination perception, hesitancy, perceived benefits and causes of action regarding the COVID-19 vaccine. More public health awareness regarding the safety of the COVID-19 vaccine are needed to gain public trust in the vaccination and the healthcare system.
\end{abstract}

Keywords: COVID-19, coronavirus, vaccine, pregnant, willingness, Saudi Arabia

\section{Summary}

Major government authorities including the American CDC, the UK NHS and the Saudi MOH recommended the use of the COVID-19 vaccine in pregnant women. Few studies in the literature deal with the acceptance of being vaccinated while pregnant. This study showed that pregnant women and those who are planning to be pregnant have a moderate score in terms of their COVID-19 vaccination perception, hesitancy, perceived benefits and causes of action regarding the COVID-19 vaccine. More public health awareness regarding the safety of the COVID-19 vaccines are needed to gain public trust in the vaccination and the healthcare system.
Correspondence: Mohammed Samannodi Department of Medicine, Umm Al-Qura University, Mecca, Saudi Arabia

Tel +966 I2550I000

Email mssamannodi@uqu.edu.sa 


\section{Introduction}

Since the emergence of the coronavirus (COVID-19) between mid-October and mid-November 2019 in China, ${ }^{1,2}$ it has become the main concern of the World Health Organisation (WHO), public health and governments worldwide. COVID-19 is a major threat to the public with significant morbidity and mortality. ${ }^{3}$ COVID19 has placed a major strain on countries' economies and the other services provided by the health care systems. ${ }^{4}$

So far, multiple vaccines have been produced and some of these vaccines have shown promising results in terms of safety and efficacy. ${ }^{5}$ In addition, some of the vaccines have already been approved by major drug and food authorities worldwide, such as the U.S Food and Drug Administration (FDA), Medicines and Healthcare Products Regulatory Agency (MHRA) and European Medicines Agency (EMA). ${ }^{6}$ In Saudi Arabia, only four vaccines have been authorised by the Saudi Food and Drug Authority (SFDA): the PfizerBioNTech, Oxford-AstraZeneca, Johnson \& Johnson's (Janssen) and Moderna vaccines. ${ }^{7}$ The population of Saudi Arabia is around 34.2 million and according to the Saudi Ministry of Health $(\mathrm{MOH})$, more than 28 million doses of COVID-19 vaccine have been received by the residents of the Saudi Kingdom, ${ }^{7}$ meaning that a large proportion of the Saudi population has received at least one dose of the vaccine.

In Saudi Arabia and some other Middle Eastern countries, rates of fertility and pregnancy planning are declining. Most Middle Eastern and North African countries, however, still have among the highest percentages of fertility levels worldwide. ${ }^{8,9}$ This is mainly due to social and behavioural factors such as unique social early marriage, cultural acceptance and access to contraception and educational level status. ${ }^{10,11}$ This is especially important during the pandemic as women planning for pregnancy may be at higher risk of a severe form of COVID-19 disease. ${ }^{12}$

According to the WHO recommendations, pregnant women have no increased risk of infection with COVID$19 ;{ }^{13}$ however, pregnant women with COVID-19 have an increased risk of severe COVID-19 diseases, ${ }^{12,14}$ which may result in admission to hospital or an intensive care unit (ICU). ${ }^{14}$ In addition, pregnant women with COVID19 have an increased risk of developing complications such as preterm pregnancy and other adverse pregnancy outcomes. ${ }^{15}$ Many guidelines issued a specific protocol for the management of COVID-19 in pregnant women. ${ }^{16,17}$

During the initial trials, pregnant women were excluded from the studies, with little data available about the safety of the vaccine in pregnant women. ${ }^{18}$ However, no major side effects have been reported among pregnant women and no evidence of side effects concerning male or female fertility. Additionally, major government authorities including the American Centers for Disease Control and Prevention (CDC), the UK National Health Service (NHS) and the Saudi Ministry of Health (MOH) recommended the use of the COVID-19 vaccine in pregnant women. This is especially because pregnant women are at higher risk of developing more severe diseases and other factors related to the risk of getting the infection such as the emergence of new strains, which highlights the importance of receiving the vaccination. ${ }^{19}$ Maternal immunization protect new-borns from several infectious diseases. ${ }^{20}$ Additionally, pregnant women with COVID-19 were more likely to be hospitalized and at increased risk of intensive care unit (ICU) admission and receipt of mechanical ventilation compared with non-pregnant women of reproductive age. ${ }^{20}$ Previous studies in the Middle East and Saudi Arabia specifically explore multiple social, mental and clinical outcomes associated with the COVID-19 pandemic. ${ }^{21-29}$ However, few studies in the literature deal with the acceptance of being vaccinated while pregnant or planning for pregnancy. The results of a study using a large web-based survey involving a sample of 17,871 responses from 16 countries $^{30}$ showed that $52.0 \%$ of pregnant women and $73.4 \%$ of non-pregnant women intended to receive the vaccine. The main factors related to receiving the vaccine included safety and effectiveness, worry about COVID-19, compliance with mask guidelines and trust of public health agencies and health science in the country. ${ }^{30}$ Previous studies on the acceptance of the COVID-19 vaccine among pregnant women in Saudi Arabia are lacking. This study aimed to investigate the acceptance rate of the COVID-19 vaccine among pregnant women and those planning for pregnancy in Saudi Arabia.

\section{Method Study Design}

A cross-sectional study using an online self-administered questionnaire was conducted in Saudi Arabia between 12 June and 1 August 2021.

\section{Sampling Strategy}

A convenience sampling technique was used to recruit the study participants in this study. Women aged 18 years and above were invited to participate in the study. The 
inclusion criteria were highlighted in the invitation letter that was sent along with the study survey link by the researcher. Social media platforms (Facebook, WhatsApp and Twitter) were used to recruit the targeted study participants. The participants were encouraged to participate in the study to assess their acceptance of the COVID-19 vaccine, which will help in providing recommendations for educational intervention to increase the acceptability of vaccination, which will ultimately reflect positively on the whole society. No incentive was provided to the participants to be involved in the study.

\section{Questionnaire Tool}

A previously validated Arabic questionnaire by Almaghaslah et al was adapted and used in this study. ${ }^{31}$ The Almaghaslah et al questionnaire was developed based on a previous systematic review of confidence and receptivity for COVID-19 vaccines ${ }^{32}$ and another nationwide online survey in China on COVID-19 vaccine demand and hesitancy. ${ }^{33}$

The questionnaire tool in this study consisted of five sections. The first section described the demographic characteristics of the study participants (five items). The second section explored participants' perceptions about COVID-19 (three items). The third section explored participants' hesitancy about receiving the COVID-19 vaccine (nine items). The fourth section explored participants' perceived benefits of receiving the COVID-19 vaccine (four items). The last section explored participants' motivations and causes of action for receiving the COVID-19 vaccine (three items). Each item was scored using a fivepoint Likert scale ranging from one (strongly disagree) to five (strongly agree). The possible scores for each section were 15 (perception), 45 (reasons for hesitancy), 20 (perceived benefits), and 15 (causes of action). Regarding the second section (participants' perceptions about COVID-19), the higher the score the weaker the perception about the seriousness of the COVID-19 situation. Regarding the third section (participants' hesitancy about receiving the COVID-19 vaccine), the higher the score the greater the hesitancy to receive the vaccine. Regarding the fourth section (participants' perceived benefits of receiving the COVID-19 vaccine), the higher the score the stronger the perception about the perceived benefits of the vaccine. Regarding the last section (participants' motivations and causes of action for receiving the COVID-19 vaccine), the higher the score the lower the motivation or likelihood to take action to receive the vaccine. The original questionnaire items (participants' perceptions about COVID-19 and the COVID-19 vaccination, vaccine confidence, its associated benefits and causes of action) were based on health belief models. ${ }^{34,35}$

\section{Statistical Analysis}

Data were analysed using Statistical Package for Social Science (SPSS) software, version 27 (IBM Corp, Armonk, NY, USA). Categorical variables were reported as frequencies and percentages. Continuous data were reported as mean \pm standard deviation (SD). Independent samples $t$-test/oneway analysis of variance (ANOVA) were used to compare the mean scores between different demographic groups. A confidence interval of $95 \%(\mathrm{P}<0.05)$ was applied to represent the statistical significance of the results, and the level of significance was predetermined as $5 \%$.

\section{Results}

A total of 431 women meeting the inclusion criteria were involved in this study. The majority (73.8\%) were aged below 40 years. Around half of the study sample (49.9\%) reported that they are pregnant or planning to be pregnant. The most common chronic diseases were hypertension and diabetes mellitus with $7.7 \%$ and $5.1 \%$, respectively. Around one-quarter of the study sample (23.7\%) reported a history of COVID-19 infection. More than half of the study sample (57.1\%) received COVID-19 vaccination. For further details on the demographic characteristics of the study sample, refer to Table 1 .

\section{COVID-19 Vaccination Perception, Hesitancy, Perceived Benefits and Causes of Action}

The study participants showed moderate scores in terms of their COVID-19 vaccination perception, hesitancy, perceived benefits and causes of action, ranging from 53.3\% to $65.0 \%$. The mean perception score for all participants was 8.0 (SD: 2.8 ) out of 15 (53.3\%), as seen in Figure 1. The mean hesitancy score for all participants was 27.6 (SD: 7.3) out of 45 (61.3\%), as seen in Figure 2. The mean perceived benefits score for all participants was 13.0 (SD: 4.5$)$ out of 20 (65.0\%), as seen in Figure 3. The mean causes of action score for all participants was 9.0 (SD: 3.7) out of 15 (60.0\%), as seen in Figure 4.

Comparing COVID-19 vaccination perception, hesitancy, perceived benefits and causes of action for those who are pregnant or planning to be pregnant with others, pregnant 
Table I Demographic Characteristics for the Study Participants

\begin{tabular}{|l|l|}
\hline Demographic Variable & Frequency (\%) \\
\hline Age & $138(32.0 \%)$ \\
\hline $18-29$ years & $180(41.8 \%)$ \\
$30-39$ years & $71(16.5 \%)$ \\
$40-49$ years & $42(9.7 \%)$ \\
50 years and over & $214(49.9 \%)$ \\
\hline Are you pregnant or planning for pregnancy? \\
\hline Yes & $33(7.7 \%)$ \\
\hline Chronic diseases history & $22(5.1 \%)$ \\
\hline Hypertension (yes) & $21(4.9 \%)$ \\
Diabetes mellitus (yes) & $16(3.7 \%)$ \\
Gastrointestinal tract diseases (yes) & $9(2.1 \%)$ \\
Dyslipidemia (yes) & $8(1.9 \%)$ \\
Immune system diseases (yes) & $7(1.6 \%)$ \\
Cardiovascular diseases (yes) & $32(7.4 \%)$ \\
\hline Central nervous diseases (yes) & $185(42.9 \%)$ \\
Others & $183(42.5 \%)$ \\
\hline Previous COVID-19 infection history & $63(14.6 \%)$ \\
\hline Yes & $102(23.7 \%)$ \\
\hline CoviD- 19 vaccination history & \\
\hline No & \\
One dose & \\
\hline Two doses & \\
\hline
\end{tabular}

women or those planning to be pregnant are more hesitant to receive COVID-19 vaccination ( $\mathrm{p}=0.001)$, as seen in Table 2 .

To explore the role of demographic characteristics of pregnant women or those who are planning to be pregnant on COVID-19 vaccination perception, hesitancy, perceived benefits and causes of action, I applied independent samples $t$-test/one-way analysis of variance (ANOVA) test. Those who reported a history of COVID-19 infection had higher perception scores (weakest perception about the seriousness of COVID-19 situation) $(p<0.001)$. Those who reported receiving the COVID-19 vaccine showed lower hesitancy scores $(\mathrm{p}<0.001)$. Those aged below 29 years who reported receiving the COVID-19 vaccine showed higher perceived benefit scores $(p<0.05)$. On the other hand, participants' demographic characteristics did not affect their causes of action score, as seen in Table 3.

\section{Discussion}

In this cross-sectional web-based survey, the study participants showed moderate scores in terms of their COVID-
19 vaccination perception, hesitancy, perceived benefits and causes of action that ranged between $53.3 \%$ and $65.0 \%$. These results are in line with previous studies, ${ }^{36,37}$ including a study conducted in Saudi Arabia showing that around $50 \%$ of the sample size of the study were hesitant to receive the vaccine. ${ }^{38}$ Another study conducted using an online survey that included more than 3000 participants in Jordan reported a low rate of acceptability of the COVID-19 vaccine (37\%). ${ }^{39}$ Although these studies are similar to this study in terms of study design, data collection methods and geographical location, they were conducted on the general population, while this study was conducted on females only. A recent study conducted in the United States among a similar study population that explored COVID-19 vaccination acceptance among pregnant, non-pregnant and breastfeeding women reported that non-pregnant women were most likely to accept vaccination $(76.2 \%)$, with breastfeeding women the second most likely to accept vaccination (55.2\%); pregnant women had the lowest rate of vaccine acceptance $(44.3 \%) .{ }^{40}$ Another study in the US conducted on 939 pregnant women reported that only $41 \%$ of the participants would get a vaccine, and $82.0 \%$ of the participants were concerned about vaccine safety for their pregnancy. ${ }^{41}$

This study showed that pregnant women and those planning to get pregnant had higher scores of hesitancy regarding taking the vaccine in comparison to women who are not pregnant or not planning to be pregnant. One of the most important factors that increase hesitancy to receive vaccination are problems of trust and hearing or reading about negative events from different sources. ${ }^{42}$ Previous studies investigating the acceptance of taking the COVID19 vaccine have shown similar results. ${ }^{30,40,43-45}$ One study conducted in Turkey in 2021 reported a lower rate of COVID-19 vaccine acceptability, with only $37 \%$ stating that they intend to receive the vaccine if it were recommended for pregnant women. ${ }^{45}$ Similar results were reported in a large study that included 16 countries across the world, with only $52.0 \%$ of pregnant women reporting that they will take the vaccine compared to $73.4 \%$ of nonpregnant women. ${ }^{30}$ These results can be explained by the fact that people have concerns regarding the effectiveness and the safety of the vaccine, especially that the vaccine was developed rapidly and received accelerated approval. $^{45}$ A recent qualitative study among pregnant women in Spain assessing the acceptability of participating in COVID-19 clinical trials reported that participating women had limited knowledge about COVID-19 and were 


\section{Strongly agree Agree $\square$ Neutral Disagree $\square$ Strongly disagree}

I HAVE HAD COVID-19 INFECTION AND I THINK I'VE DEVELOPED IMMUNITY AGAINST IT

ALL PEOPLE I KNOW WHO GOT COVID-19, THEY GOT THE MILD FORM

COVID-19 INFECTION IS NOT SERIOUS SO I DON'T THINK I SHOULD TAKE THE VACCINE

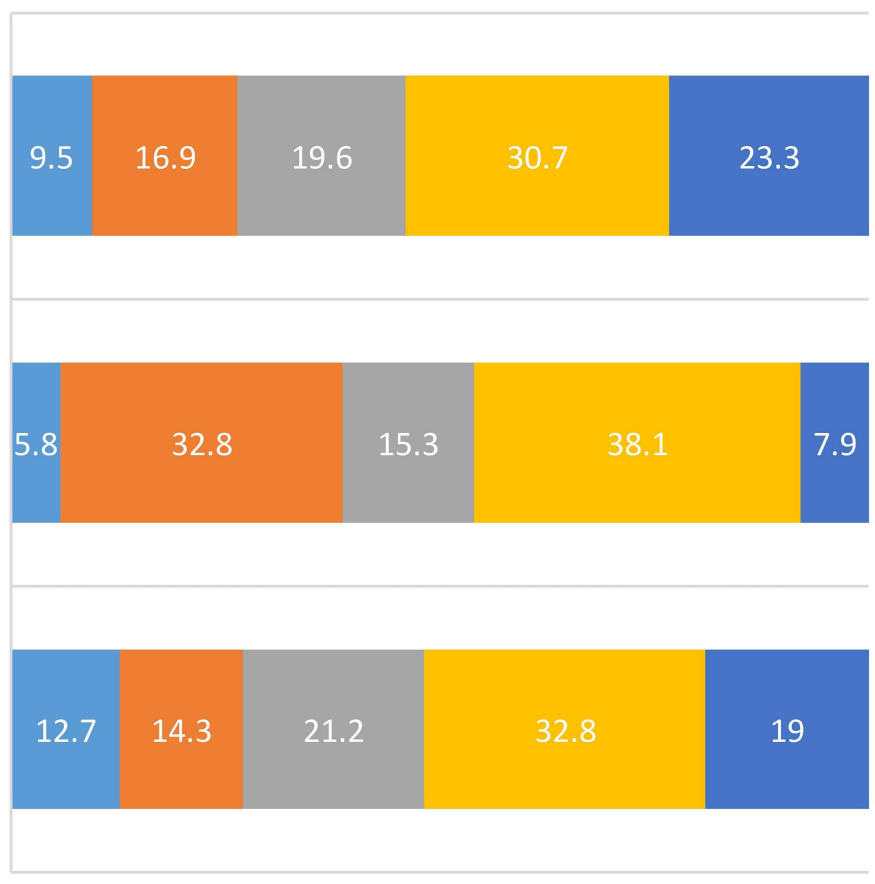

Figure I Perception about the seriousness of COVID-19 situation.

\section{- Strongly agree $\square$ Agree $\square$ Neutral $\square$ Disagree $\square$ Strongly disagree}

I HAVE HEARD THE VACCINE IS UNSAFE ON ME AND ON THE BABY DURING PREGNANCY SO I DO NOT WANT TO TAKE IT

I HAVE FOOD ALLERGY OR MEDICATIONS ALLERGY SO I CANNOT TAKE THE VACCINE

I HAVE HEARD ON SOCIAL MEDIA THAT THE VACCINE IS NOT SAFE AS IT WOULD CONTAIN THE COVID-19 VIRUS

I HAVE HEARD THAT BLOOD CLOT IS A COMMON SIDE EFFECT OF THE VACCINE

THE VACCINE HAS MAGNETIC PIECE WHICH CAN SPY ON US

I AM NOT AWARE ABOUT THE EFFECTIVENESS OF THE VACCINE ON PREGNANT WOMEN

THE VACCINE APPROVAL PROCESS WAS FAST SO, THE SAFETY OF THE VACCINE WAS NOT ASSESSED ADEQUATELY

I AM NOT SURE ABOUT THE COMPONENTS OF THE VACCINE

I AM VERY STRICT TO PRECAUTIONS ( MASK, HAND WASHING AND SOCIAL DISTANCING) SO I DO NOT NEED THE VACCINE

Figure 2 Reasons for hesitancy from receiving COVID-19 vaccine.

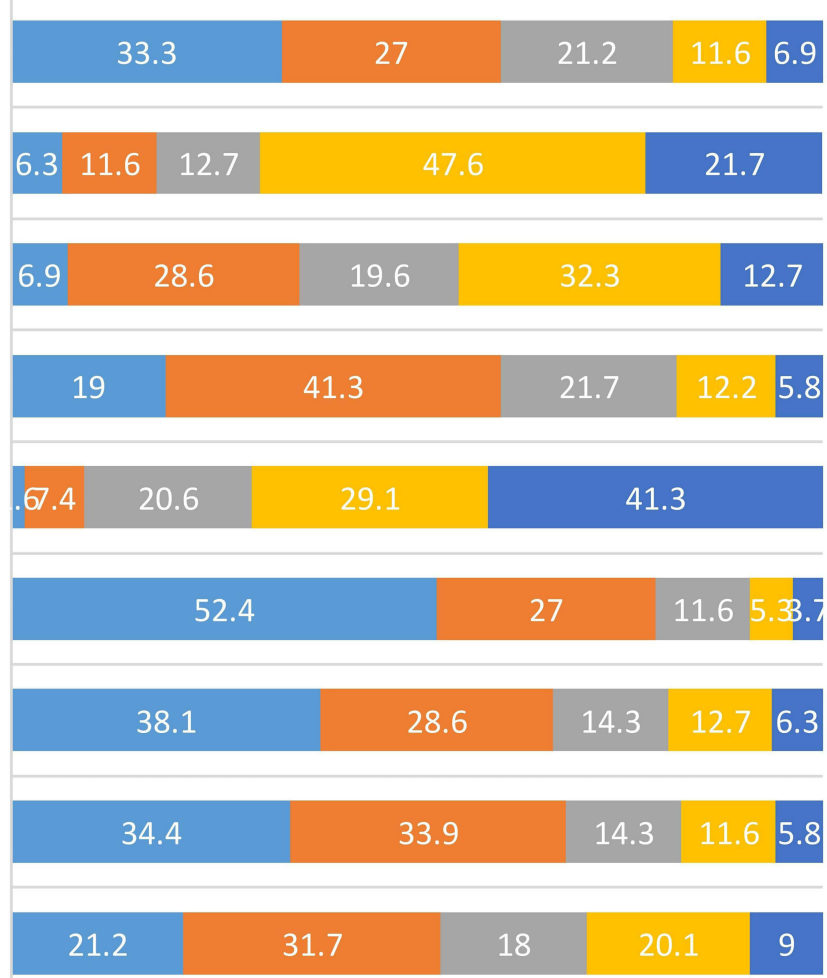


Vaccination would ease the precautionary measures including lock down, quarantine, work permit and travel ban

Complications of COVID-19 are more serious in pregnant women so vaccine will protect me against them

Vaccination decreases my chance of getting COVID-19 or its complication

Taking the vaccine would make me less worried about catching COVID-19

Strongly agree $\square$ Agree $\square$ Neutral $\square$ Disagree $\square$ Strongly disagree

I WILL ONLY TAKE THE COVID-19 VACCINE IF IT WAS MADE MANDATORY

I WILL ONLY TAKE THE COVID-19 VACCINE IF THE VACCINE IS TAKEN BY MANY IN THE PUBLIC

I WILL ONLY TAKE THE COVID-19 VACCINE IF I WAS GIVEN ADEQUATE INFORMATION ABOUT IT

- Strongly agree $\square$ Agree $\square$ Neutral $\square$ Disagree $\square$ Strongly disagree

Figure 3 Perceived benefit from receiving COVID-19 vaccine.

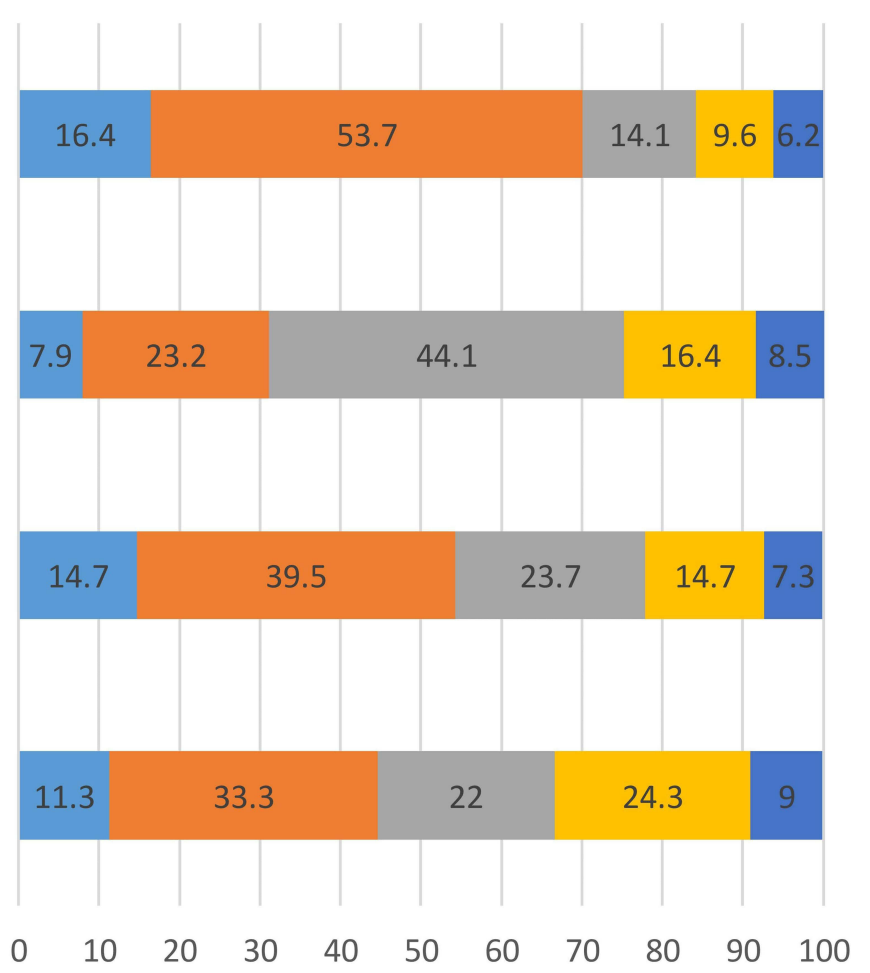

$\begin{array}{lllllllllll}0 & 10 & 20 & 30 & 40 & 50 & 60 & 70 & 80 & 90 & 100\end{array}$

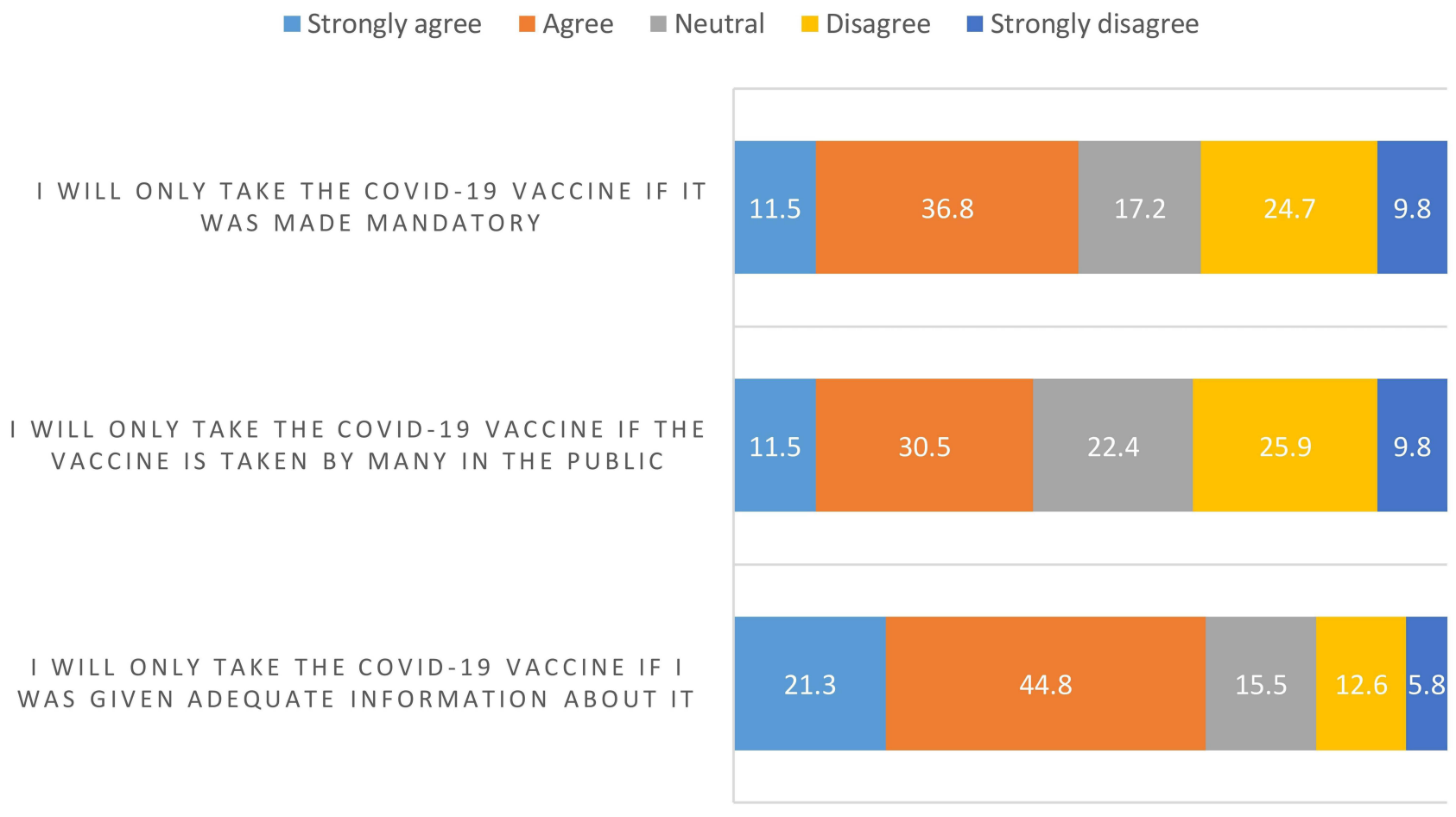

Figure 4 Causes of action and motivation to receive COVID-19 vaccine. 
Table 2 Mean Vaccination Perception, Hesitancy, Perceived Benefit, and Cause of Action Score for All Participants (N= 378)

\begin{tabular}{|l|l|l|l|l|}
\hline \multirow{2}{*}{ Sub-Scale } & All Participants & $\begin{array}{l}\text { Pregnant or Planning to } \\
\text { Be Pregnant }\end{array}$ & $\begin{array}{l}\text { Not Pregnant or Planning to } \\
\text { Be Pregnant }\end{array}$ & P-value \\
\cline { 2 - 5 } & Mean Score (SD) & Mean Score (SD) & Mean Score (SD) \\
\hline Perception score & $8.0(2.8)$ & $8.3(2.8)$ & $7.7(2.9)$ & 0.057 \\
Hesitancy score & $27.6(7.3)$ & $28.8(7.4)$ & $26.2(6.9)$ & $0.00 I^{*}$ \\
Perceived benefit score & $13.0(4.5)$ & $12.9(4.2)$ & $13.1(4.9)$ & 0.658 \\
Causes of action score & $9.0(3.7)$ & $9.4(3.5)$ & $8.7(3.8)$ & 0.062 \\
\hline
\end{tabular}

Note: ${ }^{*} p<0.01$.

Abbreviation: SD, standard deviation.

Table 3 Mean Vaccination Perception, Hesitancy, Perceived Benefit and Cause of Action Score Stratified by Demographic Characteristics for Women Who are Pregnant or Planning to $\mathrm{Be}(\mathrm{N}=189)$

\begin{tabular}{|c|c|c|c|c|c|c|c|c|}
\hline $\begin{array}{l}\text { Demographic } \\
\text { Variable }\end{array}$ & $\begin{array}{c}\text { Mean } \\
\text { Perception } \\
\text { Score (SD) }\end{array}$ & p-value & $\begin{array}{c}\text { Mean } \\
\text { Hesitancy } \\
\text { Score (SD) }\end{array}$ & p-value & $\begin{array}{c}\text { Mean Perceived } \\
\text { Benefit Score } \\
\text { (SD) }\end{array}$ & p-value & $\begin{array}{c}\text { Mean Causes of } \\
\text { Action Score } \\
\text { (SD) }\end{array}$ & p-value \\
\hline \multicolumn{9}{|l|}{ Age } \\
\hline 18-29 years & $7.8(2.7)$ & $0.27 \mathrm{I}$ & $28.4(6.8)$ & $0.77 I$ & I4.0 (3.4) & $0.024^{*}$ & $9.6(3.4)$ & 0.390 \\
\hline 30-39 years & $8.5(2.8)$ & & 29.1 (7.7) & & $12.4(4.5)$ & & 9.1 (3.7) & \\
\hline 40-49 years & $8.6(2.8)$ & & $29.5(7.5)$ & & 11.9 (3.8) & & $10.3(2.6)$ & \\
\hline \multicolumn{9}{|c|}{ Previous COVID-19 infection history } \\
\hline No & $7.8(2.7)$ & 0.000 ** & $28.6(7.6)$ & 0.318 & $13.0(4.1)$ & 0.591 & $9.4(3.4)$ & $0.88 I$ \\
\hline Yes & $9.8(2.5)$ & & $29.8(6.7)$ & & $12.6(4.4)$ & & $9.3(3.9)$ & \\
\hline \multicolumn{9}{|c|}{ COVID-I 9 vaccination history } \\
\hline No & $8.6(2.8)$ & 0.073 & $30.6(6.7)$ & $0.000 * *$ & $12.3(4.3)$ & $0.011 *$ & $9.3(3.5)$ & 0.135 \\
\hline One dose & $7.7(2.7)$ & & $26.1(7.2)$ & & I3.8 (3.7) & & 10.0 & \\
\hline Two doses & $7.5(1.8)$ & & $23.1(8.4)$ & & $15.2(3.0)$ & & $7.8(4.2)$ & \\
\hline
\end{tabular}

Note: ${ }^{*}<<0.05, * * p<0.001$.

Abbreviation: SD, standard deviation.

uncertain if pregnancy was a risk factor for acquiring the infection or developing the severe disease. ${ }^{46}$ The same study showed that the low level of knowledge among pregnant women has led to uncertainties and emotional suffering, which ultimately affected their willingness to participate in drug-related clinical trials on COVID-19, regardless of the drug under study. ${ }^{46}$

These results were consistent with previous studies conducted on the general population, especially among females. ${ }^{47}$ Clinical data on the safety of the COVID-19 vaccine among pregnant women showed no difference in side effects between pregnant and non-pregnant women in post-vaccination status; ${ }^{48}$ however, this was not extensively investigated. In addition, it was reported that a higher incidence of fever was observed among pregnant women in comparison to non-pregnant women, ${ }^{49,50}$ which may increase concerns regarding the safety of the vaccine among pregnant women. Future studies are urged to confirm the safety of the vaccine.

Some side effects have been associated with the consumption of COVID-19 vaccines, such as thrombosis and its association with the AstraZeneca vaccine. ${ }^{51}$ Although these events are rare, the intensive coverage of COVID-19 side effects on social media and other platforms may have had a negative influence on decisions of the public regarding the safety of the vaccine. ${ }^{51}$ This may have been specifically related to the Saudi population as one of the main vaccines that were distributed in the Kingdom of Saudi Arabia is the AstraZeneca vaccine. 
This study found that the majority of the study sample have strong perceptions about the effectiveness of the vaccine; however, around (60\%) were not willing to take action. A possible explanation of the hesitancy about the COVID-19 vaccine is that more data are being published about the breakthrough of the COVID-19, and the mutation of the virus into new variants. In addition, it may be attributed to the fact that, although people believe in the efficiency of the government response and preparedness ${ }^{52}$ and the seriousness of the COVID-19 vaccine, they have concerns regarding the safety of the vaccine, which may highlight the need for more public awareness regarding the safety and efficacy of the vaccine and the role of vaccination in the termination of the pandemic.

This study highlighted that those who are aged below 29 years and reported receiving the COVID-19 vaccine showed higher perceived benefits scores. This was in line with a previous study from Jordan, which showed that those aged over 35 years were less likely to accept the vaccine. ${ }^{39}$ On the other hand, participants' demographic characteristics did not affect their causes of action score, as seen in Table 3. A recent systematic review has identified an association between sociodemographic characteristics and acceptance of COVID-19 vaccination. It reported that being male, being elderly, having a higher income, having a higher education level, being a physician (compared with other healthcare professions), having private insurance and having prior vaccination history were important predictors of COVID-19 vaccination acceptance. ${ }^{53}$

It has have been documented that pregnant women have no increase incidence of COVID-19 infection in comparison to the general population. However, it has been documented that pregnant women who contract the virus may have more severe forms of COVID-19 diseases. ${ }^{16}$ In addition, major guidelines recommend the use of the vaccine as several reports from large real-world data studies showed no increased risks or concerns regarding the safety of the vaccine among pregnant women. However, as pregnant women were not included in the trials of the vaccines, ${ }^{18}$ weighting the risk-benefit of receiving the vaccine may be a crucial decision for pregnant women, especially during this time of the pandemic as post-vaccination and safety data are still limited. ${ }^{16}$

\section{Limitations}

This study has some limitations. First, it was crosssectional in study design, and participants were asked to complete an online questionnaire. A self-administered questionnaire through an online platform could be biased, so the study results may not be representative of all members of the Saudi population who meet the inclusion criteria. However, as the data collection occurred during the pandemic, we assume that everyone was using virtual meetings, social networking and online platforms, and we assume that we still targeted a well-representative sample. Second, the study was anonymous and did not gather in-depth clinical information from participants. Third, the sample size was small, so the study's results may have limited generalisability. Fourth, the researcher was not able to estimate the proportion of pregnant women from the study sample. Finally, the researcher was not able to adjust for important confounding variable such as the educational level, the job role and social- economic profile in the population study as such data was not collected from the participants.

\section{Conclusion}

This study showed that pregnant women and those who are planning for pregnancy have a moderate score in terms of their COVID-19 vaccination perception, hesitancy, perceived benefits and causes of action regarding the COVID19 vaccine, which reflects a moderate attitude towards vaccination acceptance. Educational and public awareness campaigns should be intensified using various media platforms and through healthcare professionals to the general population. Specific efforts should be directed towards high-risk populations including pregnant women and those who are planning for pregnancy. This will enhance public trust in the vaccination and the healthcare system and increase the vaccination rate. Similar future studies in different regions in Saudi Arabia are recommended.

\section{Data Sharing Statement}

No further data are available.

\section{Ethics Approval and Consent to Participate}

The study was approved by the institutional ethical committee (Institutional Review Board) with approval number HAPO-02-K-012-2021-06697 (Umm AlQura University). All participants received information about the aim the study and a consent form was completed and signed by each participant. This study was conducted in accordance with the Declaration of Helsinki. 


\section{Funding}

There is no funding to report.

\section{Disclosure}

The author declares no conflicts of interest for this work.

\section{References}

1. Morens DM, Breman JG, Calisher $\mathrm{CH}$, et al. The origin of COVID-19 and why it matters. Am J Trop Med Hyg. 2020;103 (3):955-959. doi:10.4269/ajtmh.20-0849

2. Pekar J, Worobey M, Moshiri N, et al. Timing the SARS-CoV-2 index case in Hubei province. Science. 2021;372(6540):412-417. doi:10.1126/science.abf8003

3. Matta S, Chopra KK, Arora VK. Morbidity and mortality trends of Covid 19 in top 10 countries. Indian J Tuberc. 2020;67(4S):S167S172. doi:10.1016/j.ijtb.2020.09.031

4. Singh K, Kondal D, Mohan S, et al. Health, psychosocial, and economic impacts of the COVID-19 pandemic on people with chronic conditions in India: a mixed methods study. BMC Public Health. 2021;21(1):685. doi:10.1186/s12889-021-10708-w

5. Yan ZP, Yang M, Lai CL. COVID-19 Vaccines: a review of the safety and efficacy of current clinical trials. Pharmaceuticals. 2021;14 (5):406. doi:10.3390/ph14050406

6. Lai CC, Chen IT, Chao CM, et al. COVID-19 vaccines: concerns beyond protective efficacy and safety. Expert Rev Vaccines. 2021;20 (8):1-13.

7. MOH. COVID-19 vaccine; 2021 [September 10, 2021]. Available from: https://www.moh.gov.sa/en/HealthAwareness/EducationalContent/ PublicHealth/Pages/018.aspx. Accessed November 15, 2021.

8. Serour GI. Medical and socio-cultural aspects of infertility in the Middle East. ESHRE Monogr. 2008;2008(1):34-41. doi:10.1093/ humrep/den 143

9. Eberstadt N, Shah A. Fertility decline in the Muslim world: a veritable sea-change, still curiously unnoticed. SSRN. 2011. doi: $10.2139 /$ ssrn.2022408

10. Khraif R, Abdul Salam A, Al-Mutairi A, et al. Fertility behaviour of working women in Saudi Arabia: a special case of King Saud University, Riyadh. Hum Fertil. 2019;22(4):246-254. doi:10.1080/ 14647273.2018.1449971

11. The Department of Economic and Social Affairs of the United Nations. World fertility and family planning 2020. 2020; Available from: https://www.un.org/en/development/desa/population/publica tions/pdf/family/World_Fertility_and_Family_Planning_2020_ Highlights.pdf. Accessed November 15, 2021.

12. Mayoclinic. Pregnancy and COVID-19: What are the risks? 2021 [October 23, 2021]; Available from: https://www.mayoclinic.org/dis eases-conditions/coronavirus/in-depth/pregnancy-and-covid-19/art20482639. Accessed November 15, 2021.

13. World Health Organization. Coronavirus disease (COVID-19): pregnancy and childbirth; 2020. Available from: https://www.who.int/ news-room/q-a-detail/coronavirus-disease-covid-19-pregnancy-andchildbirth.

14. Blackadar K. Pregnant women with COVID-19 at increased risk of hospitalization, ICU admission and early labour; 2020 [December 14, 2020 October 23, 2021]. Available from: https://www.med.ubc.ca/ news/pregnant-women-with-covid-19-at-increased-risk-ofhospitalization-icu-admission-and-early-labour/. Accessed November $15,2021$.

15. Shimabukuro TT, Kim SY, Myers TR, et al. Preliminary findings of mRNA Covid-19 vaccine safety in Pregnant persons. $N$ Engl J Med. 2021;384(24):2273-2282. doi:10.1056/NEJMoa2104983
16. Gynaecologists RCOG. Coronavirus infection and pregnancy; 2021 [cited 2021 August 2021]; Available from: https://www.rcog.org.uk/ en/guidelines-research-services/guidelines/coronavirus-pregnancy /covid-19-virus-infection-and-pregnancy/. Accessed November 15, 2021.

17. The American College of Obstetricians and Gynecologists (ACOG). Novel Coronavirus 2019 (COVID-19); 2021 [cited 2021 August 2021]; Available from: https://www.acog.org/clinical/ clinical-guidance/practice-advisory/articles/2020/03/novelcoronavirus-2019. Accessed November 15, 2021.

18. Whitehead CL, Walker SP. Consider pregnancy in COVID-19 therapeutic drug and vaccine trials. Lancet. 2020;395(10237):e92. doi:10.1016/S0140-6736(20)31029-1

19. Harris P, Moss D. Managing through the Covid second wave: public affairs and the challenge of Covid vaccination. J Public Aff. 2021;21 (1):e2642. doi:10.1002/pa.2642

20. Ciarambino T, Crispino P, Giordano M. Viral Infection, COVID-19 in pregnancy and lactating women: What is known? COVID. 2021;1 (1):230-245. doi:10.3390/covid1010019

21. Naser AY, Dahmash EZ, Al-Rousan R, et al. Mental health status of the general population, healthcare professionals, and university students during 2019 coronavirus disease outbreak in Jordan: a cross-sectional study. Brain Behav. 2020;10(8):e01730. doi:10.1002/ brb3.1730

22. Shabrawishi M, Al-Gethamy MM, Naser AY, et al. Clinical, radiological and therapeutic characteristics of patients with COVID-19 in Saudi Arabia. PLoS One. 2020;15(8):e0237130. doi:10.1371/journal. pone. 0237130

23. Alyami MH, Naser AY, Orabi MAA, et al. Epidemiology of COVID-19 in the Kingdom of Saudi Arabia: an ecological study. Front Public Health. 2020;8:506. doi:10.3389/fpubh.2020.00506

24. Naser AY, Al-Hadithi HT, Dahmash EZ, et al. The effect of the 2019 coronavirus disease outbreak on social relationships: a cross-sectional study in Jordan. Int J Soc Psychiatry. 2020:20764020966631. doi:10.1177/0020764020966631

25. Alsairafi Z, Naser AY, Alsaleh FM, et al. Mental health status of healthcare professionals and students of health sciences faculties in Kuwait during the COVID-19 pandemic. Int J Environ Res Public Health. 2021;18(4):2203. doi:10.3390/ijerph18042203

26. Alwafi H, Naser AY, Qanash S, et al. Predictors of length of hospital stay, mortality, and outcomes among hospitalised COVID-19 patients in Saudi Arabia: a cross-sectional study. J Multidiscip Healthc. 2021;14:839-852. doi:10.2147/JMDH.S304788

27. Naser AY, Dahmash EZ, Alsairafi ZK, et al. Knowledge and practices during the COVID-19 outbreak in the Middle East: a cross-sectional study. Int $J$ Environ Res Public Health. 2021;18(9):4699. doi:10.3390/ijerph18094699

28. Alyami HS, Naser AY, Dahmash EZ, et al. Depression and anxiety during the COVID-19 pandemic in Saudi Arabia: a cross-sectional study. Int J Clin Pract. 2021;75(7):e14244. doi:10.1111/ijcp.14244

29. Badr OI, Alwafi H, Elrefaey WA, et al. Incidence and outcomes of pulmonary embolism among hospitalized COVID-19 patients. Int J Environ Res Public Health. 2021;18(14):7645. doi:10.3390/ ijerph 18147645

30. Skjefte M, Ngirbabul M, Akeju O, et al. COVID-19 vaccine acceptance among pregnant women and mothers of young children: results of a survey in 16 countries. Eur J Epidemiol. 2021;36(2):197-211. doi:10.1007/s10654-021-00728-6

31. Almaghaslah D, Alsayari A, Kandasamy G, et al. COVID-19 vaccine hesitancy among young adults in Saudi Arabia: a cross-sectional web-based study. Vaccines. 2021;9(4):330. doi:10.3390/ vaccines 9040330

32. Lin $\mathrm{C}$, Tu P, Beitsch L. Confidence and receptivity for COVID-19 vaccines: a rapid systematic review. Vaccines 2020;9(1):16. doi:10.3390/vaccines 9010016 
33. Lin $\mathrm{Y}, \mathrm{Hu} \mathrm{Z}$, Zhao Q, et al. Understanding COVID-19 vaccine demand and hesitancy: a nationwide online survey in China. PLoS Negl Trop Dis. 2020;14(12):e0008961. doi:10.1371/journal. pntd.0008961

34. Becker M. The health belief model and personal health behavior. Health Educ Monogr. 1974;2(4):324-508. doi:10.1177/ 109019817400200407

35. Champion V, Skinner C. The health belief model. In: Health Behavior and Health Education: Theory, Research, and Practice. 4th ed. CA, United States: Jossey-Bass; 2008.

36. Fares S, Elmnyer MM, Mohamed SS, et al. COVID-19 vaccination perception and attitude among healthcare workers in Egypt. J Prim Care Community Health. 2021;12:21501327211013303. doi:10.1177/ 21501327211013303

37. Troiano G, Nardi A. Vaccine hesitancy in the era of COVID-19. Public Health. 2021;194:245-251. doi:10.1016/j.puhe.2021.02.025

38. Magadmi RM, Kamel FO. Beliefs and barriers associated with COVID-19 vaccination among the general population in Saudi Arabia. BMC Public Health. 2021;21(1):1438. doi:10.1186/s12889021-11501-5

39. El-Elimat T, AbuAlSamen MM, Almomani BA, et al. Acceptance and attitudes toward COVID-19 vaccines: a cross-sectional study from Jordan. PLoS One. 2021;16(4):e0250555. doi:10.1371/journal. pone. 0250555

40. Sutton D, D'Alton M, Zhang Y, et al. COVID-19 vaccine acceptance among pregnant, breastfeeding, and nonpregnant reproductive-aged women. Am J Obstet Gynecol MFM. 2021;3(5):100403. doi:10.1016/ j.ajogmf.2021.100403

41. Battarbee A, Ayala NK, Miller $\mathrm{CH}$, et al. Attitudes toward COVID-19 illness and COVID-19 vaccination among pregnant women: a cross-sectional multicenter study during August-December 2020. Am J Perinatol. 2021;38(1):1-9. doi:10.1055/s-0040-1713180

42. Gencer H, Özkan S, Vardar O, et al. The effects of the COVID 19 pandemic on vaccine decisions in pregnant women. Women Birth. 2021:S1871-S5192. doi:10.1016/j.wombi.2021.05.003

43. Cooper S, Betsch C, Sambala EZ, et al. Vaccine hesitancy a potential threat to the achievements of vaccination programmes in Africa. Hum Vaccin Immunother. 2018;14(10):2355-2357. doi:10.1080/21645515.2018.1460987
44. Malik AA, McFadden SM, Elharake J, et al. Determinants of COVID-19 vaccine acceptance in the US. EClinicalMedicine. 2020;26:100495. doi:10.1016/j.eclinm.2020.100495

45. Goncu Ayhan S, Oluklu D, Atalay A, et al. COVID-19 vaccine acceptance in pregnant women. Int J Gynaecol Obstet. 2021;154 (2):291-296. doi:10.1002/ijgo.13713

46. Marbán-Castro E, Pons-Duran C, García-Otero L, et al. Acceptability of clinical trials on COVID-19 during pregnancy among pregnant women and healthcare providers: a qualitative study. Int J Environ Res Public Health. 2021;18(20):10717. doi:10.3390/ijerph182010717

47. Edwards B, Biddle N, Gray M, et al. COVID-19 vaccine hesitancy and resistance: correlates in a nationally representative longitudinal survey of the Australian population. PLoS One. 2021;16(3): e0248892. doi:10.1371/journal.pone.0248892

48. Prevention, C.f.D.C.a. Vaccine safety; 2021 [cited 2021]. Available from: https://www.cdc.gov/vaccinesafety/index.html?CDC_AA_ refVal=https $\% 3 \mathrm{~A} \% 2 \mathrm{~F} \% 2 \mathrm{Fwww} . \mathrm{cdc} . \mathrm{gov} \% 2 \mathrm{Fvaccinesafety} \% 2 \mathrm{Findex}$. htm. Accessed November 15, 2021.

49. Graham JM Jr, Edwards MJ, Edwards MJ. Teratogen update: gestational effects of maternal hyperthermia due to febrile illnesses and resultant patterns of defects in humans. Teratology. 1998;58 (5):209-221. doi:10.1002/(SICI)1096-9926(199811)58:5<209::AIDTERA 8 $>3.0 . \mathrm{CO} ; 2-\mathrm{Q}$

50. Dreier JW, Andersen AM, Berg-Beckhoff G. Systematic review and meta-analyses: fever in pregnancy and health impacts in the offspring. Pediatrics. 2014;133(3):e674-88. doi:10.1542/peds.20133205

51. Solís Arce JS, Warren SS, Meriggi NF, et al. COVID-19 vaccine acceptance and hesitancy in low- and middle-income countries. Nat Med. 2021;27(8):1385-1394. doi:10.1038/s41591-021-01454-y

52. Alshammari TM, Altebainawi AF, Alenzi KA. Importance of early precautionary actions in avoiding the spread of COVID-19: Saudi Arabia as an example. Saudi Pharm J. 2020;28(7):898-902. doi:10.1016/j.jsps.2020.05.005

53. Cascini F, Pantovic A, Al-Ajlouni Y, et al. Attitudes, acceptance and hesitancy among the general population worldwide to receive the COVID-19 vaccines and their contributing factors: a systematic review. EClinicalMedicine. 2021;40:101113. doi:10.1016/j. eclinm.2021.101113
Patient Preference and Adherence

\section{Publish your work in this journal}

Patient Preference and Adherence is an international, peer-reviewed, open access journal that focusing on the growing importance of patient preference and adherence throughout the therapeutic continuum. Patient satisfaction, acceptability, quality of life, compliance, persistence and their role in developing new therapeutic modalities and compounds to optimize clinical outcomes for existing disease states are major areas of interest for the journal. This journal has been accepted for indexing on PubMed Central. The manuscript management system is completely online and includes a very quick and fair peer-review system, which is all easy to use. Visit http:// www.dovepress.com/testimonials.php to read real quotes from published authors. 